\title{
Integrating Renewable Energy Sources in Electric Vehicles via Optimization Assisted Model
}

\author{
Zhong Qianwen \\ Department of Electronic and Communication Engineering \\ Shangdong University, Jinan, Licheng, China \\ zhongqianwen77@gmail.com
}

\begin{abstract}
Electric Vehicles (EVs) is found to be a capable method to enhance the transport systems. Nevertheless, higher supply of EVs leads to higher demand of electricity. An effectual technique to decrease this impact is to combine renewable energy sources (RESs) with charging infrastructure. This research aims to set up a dispatch policy using optimization theory for enhancing the economy of microgrid (MG) systems. The most significant intention is to lessen the functional cost of system while meeting system load requirements. Accordingly, the output constraints related to distributed power supply are optimized using Grasshopper Optimization with Genetic Algorithm (GOAGA). Further, the superiority of GOAGA is authenticated over existing works regarding wide-ranging measures. From the examination, the GOAGA model reveals a minimum cost value for $\mathrm{C}_{1}, \mathrm{C}_{2}$ and total cost over other techniques, therefore ensuring the superior economy of $\mathrm{MG}$.
\end{abstract}

Keywords: Microgrid; Renewable energy; Electric vehicles; Photo Voltaic; GOAGA model.

\begin{tabular}{ll}
\multicolumn{2}{l}{ Nomenclature } \\
\hline Abbreviation & Description \\
\hline GOAGA & Grasshopper Optimization with Genetic Algorithm \\
DE & Diesel Engine \\
DG & Distributed Generation \\
EVs & Electric vehicles \\
EES & Electric Energy Storage \\
GHG & Global Greenhouse Gas \\
HVAC & Heating, Ventilation and Air-Conditioning Systems \\
MG & Microgrid \\
MKEM & Micro-grid Key Elements Model \\
PV & Photo Voltaic \\
RD & Regulation Down \\
RU & Regulation Up \\
RES & Renewable Energy Sources \\
WT & Wind Turbine \\
\hline
\end{tabular}

\section{Introduction}

Nowadays, the transport is liable for $14 \%$ of GHG emissions [34]. The construction sector generates huge quantity of greenhouse gas emissions and is accountable for just about $35 \%$ of energy utilization owing to electric devices [3]. For energy domain, it is intended to reduce the energy and biological impact using proper strategies, depending on RES. Consequently, the implementation of HVAC systems were examined gradually in the earlier decades [9,10]. Moreover, the private transport is said to be the most important cause for contaminant, such as $\mathrm{SO}_{\mathrm{x}}, \mathrm{NO}_{\mathrm{x}}, \mathrm{CO}_{2}, \mathrm{CO}$ and particulate matters [11-13]. As this causes ecological issue, the diffusion of electricity is advantageous chiefly for crowded urban areas [14] [15].

Consequently, to diminish the ecological cost of the sector, the exploitation of EVs has turned out to be a practicable option $[16,17]$. In past decades, EVs have turn out to be widespread, mainly due to its lesser flue gas emissions and minor reliance on oil. Alternatively, a significant crisis associated with EVs 
is that, it's superior penetration increase transformer congestion and leads to heavier power demand to the grid. A capable approach to develop the effect is to amalgamate local power generation like RESs into EV charging infrastructure $[18,19]$.

Moreover, the incorporation of RESs to power EVs can assist in decreasing the pollutions, with a substantial decarbonisation effect and therefore, the effectiveness of resources could be developed [27] [28] [29]. Although EVs make zero direct emissions in urban areas, they are charged from the power grid that mostly depends on fuel-fossil power plants [20-23]. However, there is a deficient in precise analysis that takes account of interaction and integration of EVs with RESs [24,30,31].

The arrangement of the paper is specified as: Section 2 portrays the review. Section 3 explains the problem formulation and section 4 portrays the optimal tuning of power limit constraints via GOAGA algorithm. Section 5 illustrates the outcomes and the paper is concluded by section 6 .

\section{Literature Review}

\subsection{Related Works}

In 2019, Jain et al. [1] have offered a model that determined the 2-way energy storage potential of several EV's for contributing RD and RU to grid. The offered method employed a design that scheduled the power from grid by treating the mobility based electric constraints. Accordingly, 2 functioning places such as, residence and workplace were taken for stipulating the supplementary services. In addition, the performance of the modelled scheme was examined efficiently in terms of energy exploitation and cost.

In 2020, Shi et al. [2] have modelled an effective approach that enhanced the economy and security of MG systems. The uncertainties of EVs wind power and SOC were formulated as "uncertainty prediction sets". Furthermore, the adopted model has enhanced the absorption ratio of RES when regulating the discharging and charging of EVs. Thereby, minimum implementation costs were attained under varied constraints. The experimentation revealed that the offered technique considerably improved the capability and robustness over the existing schemes.

In 2020, Hariri et al. [3] have designed a new generalized systematic method for reliability evaluation in smart grid. As a most important contribution, a state matrix was developed that observed the operation modes of smart grid by employing the graph theory. In addition, a novel wide-ranging model of PHEVs was developed that calculated the entire uncertainties of the system. Moreover, the performance of the developed technique was efficiently analyzed regarding sensitivity and precision.

In 2019, Buonomano et al. [4] have analysed the financial, environmental and energy performances of forthcoming state, in which EV's were related with efficient buildings equipped with EES. The financial system was dynamically simulated within the "TRNSYS environment", wherein most important consideration was offered to the appropriate system control policies that intended at optimizing solar power for electricity purpose. At last, the development of the offered model was verified in terms of sensitivity analysis.

In 2019, Imane et al. [5] have modelled a smart grid design that incorporated several embed main grid and MG. In addition, unique focus was offered to MG systems by employing a MKEM. The virtualization of developed grid model dealt with the issues associated with back-feeding, PV diffusion and supply irregularities. The simulated results revealed the impact of RES integration and it emphasized the function of batteries that sustained the system consistency.

\section{Problem Formulation}

\subsection{Objective Function}

The intention of this work is to diminish the net emission and operation cost in a simultaneous way. The arithmetical modelling is described in this section.

The objective function (obj) of modelled scheme is exposed in Eq. (1), in which $\mathrm{W}_{1}$ and $\mathrm{W}_{2}$ indicate the 2 weighting coefficients that are presented to examine the impact of diverse values on the schedule system.

$$
\operatorname{obj}=\operatorname{Min}_{\mathrm{P}_{\mathrm{i}, \mathrm{PEV}} \mathrm{PV}_{\mathrm{n}, \mathrm{t}}}\left\{\mathrm{W}_{1} \mathrm{C}_{1}+\mathrm{W}_{2} \mathrm{C}_{2}\right\}
$$

The objective function $\mathrm{C}_{1}$ and $\mathrm{C}_{2}$ are defined as exposed in Eq. (2) and Eq. (3), in which $\mathrm{C}_{1}$ points out the operation cost of the system (along with the maintenance cost, operation and fuel) and $\mathrm{C}_{2}$ refers to the environmental treatment cost ( that consist of $\mathrm{NO}_{\mathrm{x}}, \mathrm{SO}_{2}$, and $\mathrm{CO}_{2}$ ). 


$$
\begin{aligned}
& \mathrm{C}_{1}=\sum_{\mathrm{t}=1}^{\mathrm{T}}\left\{\sum_{\mathrm{i}=1}^{\mathrm{M}}\left[\mathrm{O}_{\mathrm{f}}\left(\mathrm{P}_{\mathrm{i}, \mathrm{t}}\right)+\mathrm{O}_{\mathrm{OM}}\left(\mathrm{P}_{\mathrm{i}, \mathrm{t}}\right)+\mathrm{O}_{\mathrm{BAT}}\left(\mathrm{PEV}_{\mathrm{t}}\right)\right]+\mathrm{O}_{\text {grid, } \mathrm{t}}\right\} \\
& \mathrm{C}_{2}=\sum_{\mathrm{i}=1}^{\mathrm{M}} \sum_{\mathrm{g}}^{\mathrm{G}}\left(\mathrm{O}_{\mathrm{g}} \mathrm{v}_{\mathrm{i}, \mathrm{g}}\right) \mathrm{P}_{\mathrm{i}}+\sum_{\mathrm{g}}^{\mathrm{G}}\left(\mathrm{O}_{\mathrm{g}} \mathrm{v}_{\text {grid, }}\right) P_{\text {grid }}
\end{aligned}
$$

In Eq. (3), $\mathrm{v}_{\mathrm{i}, \mathrm{g}}$ refers to the discharge coefficient pollutant of $\mathrm{i}$ type DGs; $\mathrm{v}_{\text {grid, } g}$ refers to coefficients of discharge pollutants of main power grid; $\mathrm{O}_{\mathrm{g}}$ refers to treatment cost of $\mathrm{g}^{\text {th }}$ contaminant emission; $\mathrm{P}_{\mathrm{i}}$ refers to output power of $\mathrm{i}^{\text {th }}$ power supply; $\mathrm{P}_{\text {grid }}$ refers to grid power. In Eq. (2), $\mathrm{PEV}_{\mathrm{t}}$ signifies the whole discharging and charging power of EVs at timet, and $\mathrm{P}_{\mathrm{i}, \mathrm{t}}$ signifies the kind of distributed power supply that satisfied $\mathrm{P}_{\mathrm{i}, \mathrm{t}}=\left\langle\mathrm{PDE}_{\mathrm{h}, \mathrm{t}} ; \mathrm{PWT}_{1, \mathrm{t}}\right\rfloor \mathrm{t}=1,2 \ldots .24$. In addition, $\mathrm{PDE}_{\mathrm{h}, \mathrm{t}}$ signifies the $\mathrm{h}^{\text {th }} \mathrm{DE}$ output at time $\mathrm{t}$, $\mathrm{PWT}_{1, t}$ signifies the $1^{\text {th }} \mathrm{WT}$ output at time $\mathrm{t}$. The whole operation cost of the MG system in $\$(\mathrm{USA})$ take account of the fuel costs of DGs $\mathrm{O}_{\mathrm{f}}(\bullet)$, the operational and maintenance cost $\mathrm{O}_{\mathrm{OM}}(\bullet)$, the degradation cost of battery $\mathrm{O}_{\mathrm{BAT}}(\bullet)$, and the transmission cost amid main power grid and the MG. The cost functions of objective function $C_{1}$ are elucidated in Eq. (4) - Eq. (7).

$$
\begin{aligned}
& \mathrm{O}_{\mathrm{f}}(\bullet)=\left\{\mathrm{C}_{1} \mathrm{PDE}_{\mathrm{t}}^{2}+\mathrm{C}_{2} \mathrm{PDE}_{\mathrm{t}}+\mathrm{C}_{3}\right\}_{\mathrm{DE}} \\
& \mathrm{O}_{\mathrm{OM}}(\bullet)=\mathrm{K}_{\mathrm{OM}} \mathrm{P}_{\mathrm{i}, \mathrm{t}} \\
& \mathrm{O}_{\text {grid, } \mathrm{t}}= \begin{cases}\mathrm{P}_{\text {grid } \mathrm{t}}^{+} \mathrm{N}_{\text {sell,t }} & \mathrm{P}_{\mathrm{d}}>\mathrm{P}_{\mathrm{i}} \\
\mathrm{P}_{\text {grid } \mathrm{t}}^{-} \mathrm{N}_{\text {buy }, \mathrm{t}} & \mathrm{P}_{\mathrm{d}}<\mathrm{P}_{\mathrm{i}}\end{cases} \\
& \mathrm{O}_{\mathrm{BAT}}(\bullet)=\mathrm{A}_{\mathrm{n}} \mathrm{PEV}_{\mathrm{t}}^{2}+\mathrm{B}_{\mathrm{n}} \mathrm{C}_{2} \mathrm{PEV}_{\mathrm{t}}+\mathrm{C}_{\mathrm{n}}
\end{aligned}
$$

In Eq. (4), $C_{1} ; C_{2} ; C_{3}$ refers to the cost factors of DE; $A_{n} ; B_{n} ; C_{n}$ stands for the constraints of battery degradation cost; the $\mathrm{N}_{\text {buy,t }}$ and $\mathrm{N}_{\text {sell,t }}$ stands for the coefficients of transmission amongst main power grid to $\mathrm{MG}$ at time $\mathrm{t} ; \mathrm{P}_{\text {grid, } t}^{+}$and $\mathrm{P}_{\text {grid, },}^{-}$stands for the transmission power of main power grid and $\mathrm{MG}$ in that order and $\mathrm{K}_{\mathrm{OM}}$ stands for the OM cost factor. In Eq. (6), $\mathrm{P}_{\mathrm{d}}$ point out the demand power.

\subsection{Constraints}

The output parameters linked with the distributed power supply is mainly addressed in the form of power limits, which consist of the output parameters of WT, output constraint of conventional power supplies in real-time, discharging - charging power constraints of EVs and power limit of grids:

$$
\begin{aligned}
& \mathrm{P}_{\mathrm{i}, \mathrm{t}}^{\min } \leq \mathrm{P}_{\mathrm{i}, \mathrm{t}} \leq \mathrm{P}_{\mathrm{i}, \mathrm{t}}^{\max } \\
& 0 \leq \mathrm{PWT}_{\mathrm{t}} \leq \mathrm{PWT}_{\mathrm{t}}^{\mathrm{H}} \\
& \mathrm{P}_{\text {buy }}^{\min } \leq \mathrm{P}_{\text {grid }, \mathrm{t}}^{+} \leq \mathrm{P}_{\text {buy }}^{\max } \\
& \mathrm{P}_{\text {sell }}^{\min } \leq \mathrm{P}_{\text {grid }, \mathrm{t}}^{-} \leq \mathrm{P}_{\text {sell }}^{\max } \\
& 0 \leq \mathrm{PEV}_{\mathrm{d}, \mathrm{t}} \leq \mathrm{PEV}_{\mathrm{d}, \mathrm{t}}^{\max } \\
& 0 \leq \mathrm{PEV}_{\mathrm{c}, \mathrm{t}} \leq \mathrm{PEV}_{\mathrm{c}, \mathrm{t}}^{\max }
\end{aligned}
$$

Eq. (8) signifies the output constraint of DE in real-time, Eq. (9) refers to the output constraint of WT, and Eq. (10) and Eq. (11) refers to the grid power constraints of main grid and the grid power constraints of MG. Eq. (13) and Eq. (12) point out the discharging and charging power constraints of EVs in that order.

\section{Optimal Tuning of Power Limit Constraints Via GOAGA Algorithm}

\subsection{Solution Encoding}

The presented scheme intends to accomplish 5 optimal factors namely, (i) optimal allotment of WT and DE (ii) optimal achievement of PDE (iii) optimal achievement of PWT (iv) optimal $\mathrm{P}_{\text {grid,t }}^{+}$and (v) optimal $P_{\text {grid,t }}^{-}$. The input solution offered to the GOAGA algorithm is exposed in Fig. 1. The optimal allotment of WT and DE is regarded for $24 \times 5$ (24 point out the hours and 5 point out the count of DG); i.e. for each hour, 5 DGs will be subjugated and its bound lies amongst 0 and 1 . The DG with maximal 
value is allotted with the WT, whereas, the residual 4 DGs are allotted with DE. Moreover, the PDE value lies amongst $1500 \mathrm{~kW}$ and $500 \mathrm{~kW}$ and it is considered for $24 \times 4$ (for every hour, 4 DGs will be exploited). The value of PWT lie amongst 500e 3 and $500 \mathrm{e} 2$ and it is considered for $24 \times 1$ (for every hour, 1 DG is deployed). In addition, the optimal value of $\mathrm{P}_{\text {grid, }}^{+}$lie amongst $0 \mathrm{~kW}$ and $300 \mathrm{~kW}$ and the optimal value of $\mathrm{P}_{\text {grid, }}^{-}$lie amongst $0 \mathrm{~kW}$ and $150 \mathrm{~kW}$ and is measured for 24 hours.

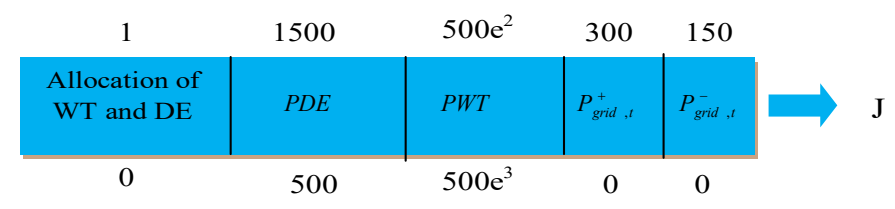

Fig. 1. Solution encoding

\subsection{GOAGA Algorithm}

GA is a heuristic optimization scheme that is usually deployed for enhance the solutions and for resolving the multi-objective issues. However, the convergence speed of GA is inferior. Moreover, the GOA model is an optimization technique depending on the activities of grasshopper swarms in nature. The convergence speed of GOA is superior and simultaneously the accurateness of detecting the solutions is high. Thereby, the GA and GOA are merged to form the GOAGA technique. Hybrid techniques are found to be capable for resolving complex optimization issues. The steps in the GOAGA model [16] are portrayed below:

Step 1: Initiate $\mathrm{Pop}_{\mathrm{i}}$ (the random population), current iteration $\mathrm{t}$, maximal value $\mathrm{cmx}$, minimal value cmn and maximal iteration count $\mathrm{L}$.

Step 2: Evaluate the search agent fitness

Step 3: The best search agent is regarded as $\mathrm{T}$

Step 4: While $(\mathrm{t}<\mathrm{L})$ move to following steps

Step 5: Constraint $\mathrm{c}$ is updated as in Eq. (14)

$$
\mathrm{c}=\mathrm{cmx}-\mathrm{t} \frac{\mathrm{cmx}-\mathrm{cmn}}{\mathrm{L}}
$$

Step 6: For (every search agent), the distance among the grasshoppers is stabilized in $[1,4]$ interval.

Step 7: The position of present search agent is updated as per Eq. (15).

$$
\operatorname{Pos}_{1}^{a}=c\left(\sum_{\substack{j=1 \\ j \neq i}}^{M} c \frac{\text { Upper }- \text { Lowera }}{2} r\left(\left|J_{j}^{a}-J_{i}^{a}\right|\right) \frac{J_{j}-J_{i}}{a_{i j}}\right)+\hat{T}_{a}
$$

Accordingly, $a_{i j}$ refers to the distance among $i^{\text {th }}$ and the $j^{\text {th }}$ grasshopper and it is described as $_{\mathrm{ij}}=\left|\mathrm{J}_{\mathrm{j}}-\mathrm{J}_{\mathrm{i}}\right|$. Moreover, $\mathrm{r}$ strength of social forces and M refers to count of grasshoppers.

Step 7: Calculate fitness by means of Eq. (1)

Step 8: Depending on minimal fitness, the best 2 solutions are found.

Step 9: Update the position of search agent by means of the cross-over of GA and again. Evaluate fitness by means of Eq. (1). The finest two solutions obtained from GA and GOA is united. Again calculate fitness and carry the search agent to its original location.

Step 10: Terminate

\section{Results and Discussions}

\subsection{Simulation Procedure}

The developed GOAGA approach for improving the economy of MG system was executed in MATLAB and the related outcomes were noticed. As per the developed model, the cost analysis was performed regarding time (hour) by distinguishing it with other existing schemes like WOA [14], DA [15], CSA [12] and GWO [13]. In addition, stochastic analysis as well as robust analysis was performed in terms of power in kilowatt $(\mathrm{kW})$. Table I exposes the environmental constraints that demonstrates the pollution and cost emission $(\mathrm{kW})$. 
Table 1. Environmental constraints

\begin{tabular}{lllll}
\hline Type & Treatment cost $(\$ / \mathrm{kg})$ & \multicolumn{4}{l}{ Coefficient to Pollutant emission $(\mathrm{g} / \mathrm{kW})$} \\
\hline & & Main grid & WT & DE \\
\cline { 2 - 2 } $\mathrm{NO}_{\mathbf{x}}$ & 1.1765 & 1.6 & 0 & 10.09 \\
$\mathrm{CO}_{2}$ & 0.0309 & 889 & 0 & 680 \\
$\mathrm{SO}_{2}$ & 0.8824 & 1.8 & 0 & 0.306 \\
\hline
\end{tabular}

\subsection{Stochastic Optimization Analysis}

The analysis for GOAGA model in terms of stochastic optimization is exposed in Table II. As per the resultants in Table II, EVs discharged throughout peak hours assists DE to meet-up the load demand that lessen the high economical cost efficiently. Meanwhile, during 23.00 to 1.00, the load demand decreases while the WT output rise. At this instance, EVs are recharged to gratify the travel requirements of users for the following day that improve the utilization rate of WT power.

Table 2. Examination on stochastic optimization

\begin{tabular}{|c|c|c|c|c|}
\hline \multicolumn{5}{|c|}{ Power in $\mathrm{kW}$} \\
\hline Time (hr) & $\mathrm{DE}$ & WT & $\mathrm{P}_{\text {grid }+}$ & Pgrid- \\
\hline 16 & 100 & 900 & 500 & 0 \\
\hline 17 & 500 & 350 & 500 & 0 \\
\hline 18 & 250 & 450 & 500 & 0 \\
\hline 19 & 100 & 900 & 500 & 0 \\
\hline 20 & 100 & 1000 & 500 & 0 \\
\hline 21 & 100 & 600 & 500 & 0 \\
\hline 22 & 100 & 600 & 500 & 0 \\
\hline 23 & 0 & 700 & 450 & 0 \\
\hline 1 & 0 & 1000 & 200 & 0 \\
\hline $\mathbf{0}$ & 0 & 1000 & 300 & 0 \\
\hline 2 & 150 & 500 & 500 & 0 \\
\hline 3 & 400 & 700 & 500 & 0 \\
\hline
\end{tabular}

\subsection{Analysis on Robustness}

The assessment for the GOAGA model regarding robustness is exposed in Table III. On evaluating the stochastic analysis with robust analysis, the resultants of robust analysis is found to meet more charging demands of EVs' when there is lesser EVs and lesser WTs discharging loads.

Table 3. Examination on robust optimization

\begin{tabular}{|c|c|c|c|c|}
\hline \multirow[b]{2}{*}{ Time (hr) } & \multicolumn{3}{|c|}{ Power in $\mathrm{kW}$} & \multirow[b]{2}{*}{$\mathrm{P}_{\text {grid- }}$} \\
\hline & $\mathrm{DE}$ & WT & $\mathrm{P}_{\text {grid+ }}$ & \\
\hline 16 & 100 & 1000 & 500 & 0 \\
\hline 17 & 600 & 250 & 500 & 0 \\
\hline 18 & 450 & 250 & 500 & 0 \\
\hline 19 & 400 & 650 & 500 & 0 \\
\hline 20 & 400 & 700 & 500 & 0 \\
\hline 21 & 200 & 250 & 500 & 0 \\
\hline 22 & 200 & 350 & 500 & 0 \\
\hline 23 & 150 & 600 & 500 & 0 \\
\hline 3 & 500 & 200 & 500 & 0 \\
\hline 2 & 250 & 400 & 500 & 0 \\
\hline 1 & 0 & 650 & 400 & 0 \\
\hline 0 & 150 & 650 & 500 & 0 \\
\hline
\end{tabular}

\subsection{Cost Analysis}

Table IV demonstrates the cost analysis of GOAGA model over compared approaches such as WOA, DA, CSA and GWO for diverse time intervals (hours). From the examination, the GOAGA model has depicted a minimal cost value for $\mathrm{C}_{1}, \mathrm{C}_{2}$ and total cost over other techniques, therefore guarantying the enhanced economy of MG. Therefore, from the evaluation, it is clear that the GOAGA model has attained improved performance in cost assessment over the existing methods. 
Table 4. Cost Analysis of developed scheme over conventional models for different hours

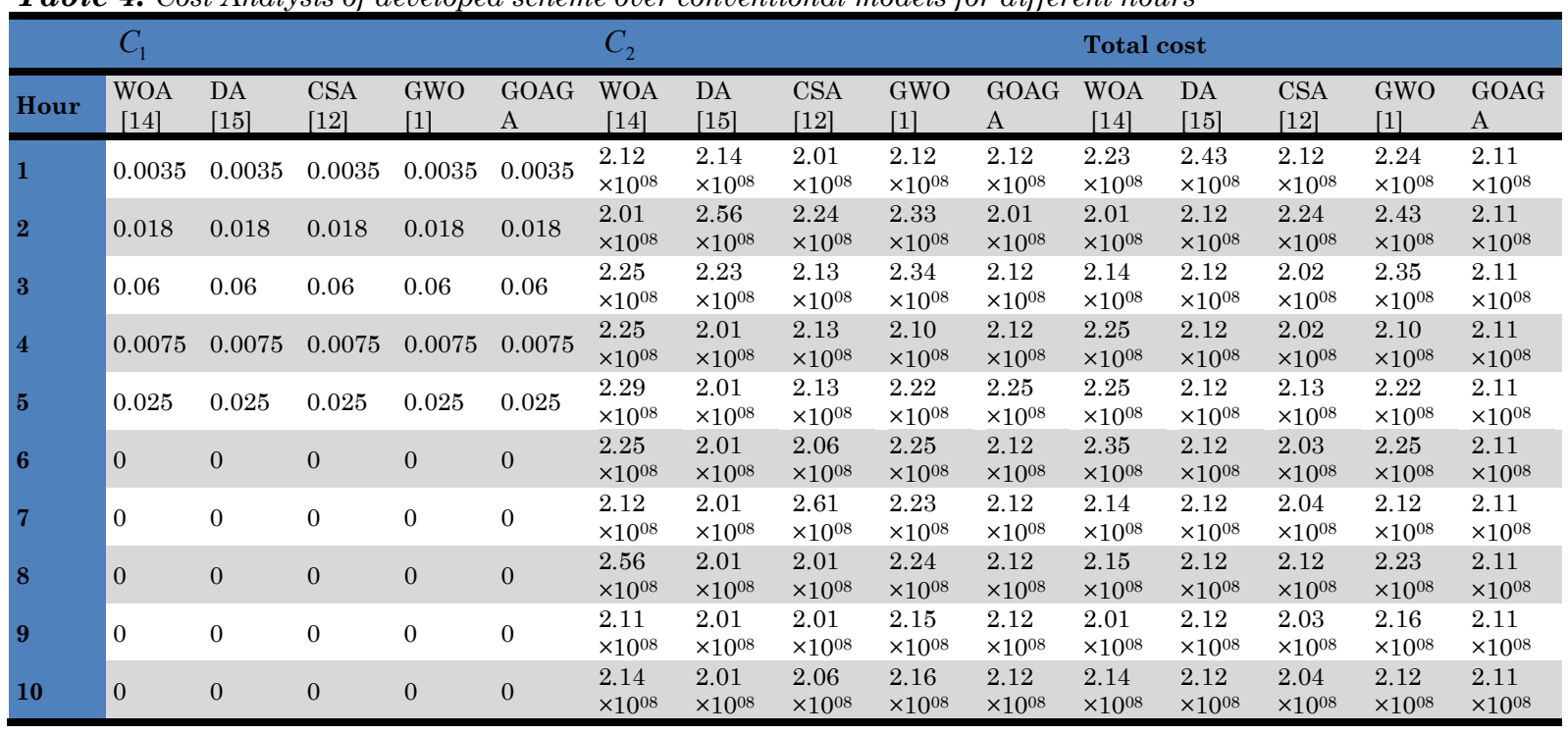

\section{Conclusion}

This work has developed a dispatch strategy that improved the economy of MG by means of CGWO model. Here, the primary objective was to diminish the operation cost of the system while satisfying the load necessities. Furthermore, the output parameters related with distributed power supply was subjected to optimization, for which GOAGA model was used. Accordingly, the performance of GOAGA model was evaluated over existing models with respect to grid and cost analysis. From the examination, the GOAGA model has revealed a minimum cost value for $\mathrm{C}_{1}, \mathrm{C}_{2}$ and total cost over other techniques, therefore ensuring the superior economy of MG. Thus, from the assessment, it is obvious that the GOAGA model has attained enhanced performance in terms of cost assessment. Moreover, EVs discharged throughout peak hours assists DE to meet-up the load demand that lessen the high economical cost efficiently. Therefore, the better outcomes establishes the efficacy of the developed dispatch model.

\section{Compliance with Ethical Standards}

Conflicts of interest: Authors declared that they have no conflict of interest.

Human participants: The conducted research follows the ethical standards and the authors ensured that they have not conducted any studies with human participants or animals.

\section{References}

[1] Prateek Jain, Ashutosh Das, Trapti Jain, "Aggregated electric vehicle resource modelling for regulation services commitment in power grid", Sustainable Cities and Society, vol. 45, pp. 439-450, February 2019.

[2] Ruifeng Shi, Shaopeng Li, Penghui Zhang, Kwang Y. Lee, "Integration of renewable energy sources and electric vehicles in V2G network with adjustable robust optimization", Renewable Energy, vol. 153, pp. 1067-1080, June 2020.

[3] Ali-Mohammad Hariri, Hamed Hashemi-Dezaki, Maryam A. Hejazi, "A novel generalized analytical reliability assessment method of smart grids including renewable and non-renewable distributed generations and plug-in hybrid electric vehicles”, Reliability Engineering \& System Safety, vol. 196, April 2020, Article 106746.

[4] A. Buonomano, F. Calise, F. L. Cappiello, A. Palombo, M. Vicidomini, "Dynamic analysis of the integration of electric vehicles in efficient buildings fed by renewables", Applied Energy, vol. 245, pp. 31-50, 1 July 2019.

[5] Imane Worighi, Abdelilah Maach, Abdelhakim Hafid, Omar Hegazy, Joeri Van Mierlo, "Integrating renewable energy in smart grid system: Architecture, virtualization and analysis", Sustainable Energy, Grids and Networks, vol. 18, June 2019, Article 100226.

[6] J. A. Domínguez-Navarro, R. Dufo-López, J. M. Yusta-Loyo, J. S. Artal-Sevil, J. L. Bernal-Agustín, "Design of an electric vehicle fast-charging station with integration of renewable energy and storage systems", International Journal of Electrical Power \& Energy Systems, vol. 105, pp. 46-58, February 2019. 
[7] Md. Monirul Islam, Xiao Zhong, Zeyi Sun, Haoyi Xiong, Wenqing Hu, "Real-time frequency regulation using aggregated electric vehicles in smart grid”, Computers \& Industrial Engineering, vol. 134, pp. 11-26, 2019.

[8] Yanchong Zheng, Yitong Shang, Ziyun Shao, Linni Jian, "A novel real-time scheduling strategy with near-linear complexity for integrating large-scale electric vehicles into smart grid”, Applied Energy, vol. 217, pp. 1-13, 1 May 2018.

[9] Omid Rahbari, Majid Vafaeipour, Noshin Omar, Marc A. Rosen, Peter Van Den Bossche, "An optimal versatile control approach for plug-in electric vehicles to integrate renewable energy sources and smart grids", Energy, vol. 134, pp. 1053-1067, 1 September 2017.

[10] Mostafa Rezaei Mozafar, Mohammad H. Moradi, M. Hadi Amini, "A simultaneous approach for optimal allocation of renewable energy sources and electric vehicle charging stations in smart grids based on improved GA-PSO algorithm”, Sustainable Cities and Society, vol. 32, pp. 627-637, July 2017.

[11] Julia K. Szinai, Colin J. R. Sheppard, Nikit Abhyankar, Anand R. Gopal, "Reduced grid operating costs and renewable energy curtailment with electric vehicle charge management”, Energy Policy, vol. 136, January 2020, Article 111051.

[12] Ramin Rajabioun, "Cuckoo Optimization Algorithm”, Applied Soft Computing, vol. 11, no. 8, pp. 5508-5518, December 2011.

[13] Seyedali Mirjalili a, Seyed Mohammad Mirjalili, Andrew Lewis, "Grey Wolf Optimizer", Advances in Engineering Software, vol. 69, pp.46-61, 2014.

[14] Seyedali Mirjalili, Andrew Lewis, "The Whale Optimization Algorithm", Advances in Engineering Software, vol. 95, pp. 51-67, May 2016.

[15] Mohammad Jafari, Mohammad Hossein Bayati Chaleshtari, "Using dragonfly algorithm for optimization of orthotropic infinite plates with a quasi-triangular cut-out”, European Journal of Mechanics - A/Solids, vol. 6, pp. 1-146, November-December 2017.

[16] M.M. Annie Alphonsa and N. MohanaSundaram, "A reformed grasshopper optimization with genetic principle for securing medical data", Journal of Information Security and Applications, Vol.47,pp.410-420,2019 